\title{
Metallomics
}

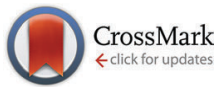

Cite this: Metallomics, 2015 7, 1431

Received 12th June 2015 Accepted 21st August 2015

DOI: $10.1039 / c 5 m t 00159 e$

www.rsc.org/metallomics

\section{HSA carbonylation with methylglyoxal and the binding/release of copper(II) ions}

\author{
Ana Z. Penezić, Vesna B. Jovanović, Ivan D. Pavićević, Jelena M. Aćimović and \\ Ljuba M. Mandić* $\dagger$
}

\begin{abstract}
The potential of carbonylation with methylglyoxal to alter HSA's binding affinity for copper(II) ions and its influence on the release of copper(II) ions from copper-HSA complexes were studied. The affinity of HSA to coordinate copper(II) decreased upon carbonylation of the Cys34-SH group. Carbonylation of copper-HSA complexes caused a decrease in Cys34-SH content, conformational changes and the release of copper(II) ions. The ratio between the percentage of reduction in the Cys34-SH group content and the percentage of release of copper(॥) from complexes is $2.12 \pm 0.28$. Because the same ratio $(1.96 \pm 0.36)$ was obtained upon oxidation of the Cys34-SH group (with no changes in HSA conformation), the binding/release of copper (II) by HSA depended mainly on the redox state of the Cys34-SH group. The contents of Cys34-SH and HSA-bound copper(I) ions in the diabetic group $(0.457 \pm 0.081 \mathrm{~mol} \mathrm{SH}$ per mol $\mathrm{HSA}, 10.7 \pm 0.01 \mathrm{mmol}$ per mol HSA, resp.) were significantly lower $(p<0.01)$ compared to the control group $(0.609 \pm 0.027 \mathrm{~mol} \mathrm{SH}$ per mol HSA; $13.4 \pm 0.01 \mathrm{mmol}$ per mol HSA, resp.). Very strong correlations between the values for HSA-SH and glycated haemoglobin, HbA1c, $(R=-0.803, p<0.01)$, and between the values for the HSA-bound copper(II) content and HSA-SH content $(R=0.841, p<0.002)$ were found in the diabetic group. Thus, HSA carbonylation leads to decrease in HSA-SH content and to the impairment of its copper(II) binding capacity that could contribute to further enhancement of oxidative and carbonyl stress in diabetes (as well as in other diseases with carbonyl stress).
\end{abstract}

\section{Introduction}

Human serum albumin (HSA) is the most abundant serum protein, with several important physiological functions. ${ }^{1,2}$ Besides regulation of oncotic pressure, it also serves as a transporter of metal ions ( $\mathrm{Cu}, \mathrm{Zn}, \mathrm{Fe}, \mathrm{Co}$, Ni etc.), fatty acids, cholesterol, hormones, drugs and bile pigments. HSA contains two binding sites for copper ions, one with high affinity, located at the $\mathrm{N}$-terminus (NT, with $1 \mathrm{pM}$ affinity), and second positioned at the interface of domains I and II (multi-metal binding site, MBS). ${ }^{3,4}$ Although ceruloplasmin represents a major pool of copper in plasma, HSA, due to its high concentration, is considered to be its second largest pool. About $15 \%$ of all blood copper is bound to HSA as $\mathrm{Cu}(\mathrm{II}) .{ }^{4}$ Copper(II) ion levels are reported to be increased in diabetes and some other pathological states, ${ }^{5,6}$ and any unbound copper(II) ions in circulation may undergo Fenton reaction causing oxidative stress by the formation of free radicals. ${ }^{7}$

Department of Biochemistry, Faculty of Chemistry, University of Belgrade, Studentski trg 12-16, Belgrade 11158, Serbia.E-mail: ljmandic@chem.bg.ac.rs; Tel: +381113336676

$\dagger$ PhD Department of Biochemistry, Faculty of Chemistry, University of Belgrade, P.O. Box 51, Studentski trg 16, 11158 Belgrade, Serbia.
Oxidative and/or carbonyl stress are believed to play an important role in pathogenesis of various diseases e.g. uraemia, ${ }^{8}$ renal failure, diabetes mellitus ${ }^{9,10}$ etc. as well as in genesis of secondary complications in diabetic patients involving microangiopathies and cardio-vascular complications. ${ }^{11}$

HSA has 35 Cys residues, 34 of them being involved in 17 intramolecular disulfide bridges, and one, Cys-34, that is redox active. With normal serum concentration between 35 and $50 \mathrm{~g} \mathrm{~L}^{-1}$, and $70-80 \%$ of its Cys34 in the reduced/sulfhydryl form, HSA represents the predominant serum protein and a major plasma antioxidant. ${ }^{1,2,12}$ Antioxidant properties of HSA depend on nucleophilic properties of Cys34 as well as on copper-binding ability. ${ }^{2,13}$ Both of these attributes may become impaired when HSA is exposed to increased glycation, leading to protein modification, formation of advanced glycated end-products (AGEs) and protein cross-linking. ${ }^{14-18}$

Diabetes mellitus is one of the most prevalent chronic diseases, affecting around 360 million people worldwide, ${ }^{19}$ of which $\sim 90-95 \%$ are categorized as type $2 .{ }^{20}$ Hyperglycemia in diabetes provokes Maillard reaction, formation of Schiff bases, and Amadori products, and finally leads to generation of AGEs. ${ }^{21}$

Methylglyoxal (MG) represents a naturally occurring $\alpha$-oxoaldehyde, generated either non-enzymatic, or from the spontaneous decomposition of triose phosphates, by autoxidation 
of carbohydrates, and glucose degradation, or by several minor metabolic pathways including the Maillard reaction and lipid peroxidation. The formation rate of MG in normal systems is $120 \mu \mathrm{mol}$ per day, but several studies have shown that this rate in diabetes is increased by 5- to 6-fold. ${ }^{22,23}$ Because of its high reactivity (20000-fold more reactive than glucose ${ }^{24}$ ), MG represents a potent modifying agent of proteins ${ }^{14,18}$ and nucleic acids. ${ }^{25}$

Thus, studies related to diabetic pathology reveal the existence of oxidative stress in these patients, decreased content of the Cys34 thiol group, ${ }^{26}$ elevated levels of serum MG and copper(II) ions, especially in type 2 diabetics. ${ }^{27,28}$ Recent studies regarding MG as modifying agent of HSA (in vitro and in diabetes), and the ability of glycated HSA to bind of copper(II) ions reported different opposite results. $^{29,30}$ Besides decrease in HSA-SH group content, carbonylation with MG leads to conformational changes in HSA molecules, ${ }^{31}$ which could also influence HSA copper binding. Therefore, the goal of this study was to determine the potential of MG, as a modifying agent, to alternate HSA's binding affinity for copper(II) ions, i.e. the potential of reaction of carbonylation to release copper(II) ions from copper-HSA complexes. The changes in the Cys34 thiol group content and in the content of copper(II) ions bound to HSA, and their ratios, as well as the changes in conformation of HSA and copper-HSA complexes during carbonylation in vitro (with $\mathrm{MG}$ ) and in diabetes type 2, were monitored. Deciphering the effect of HSA modification with MG on its ability to bind and sequester copper(II) ions in circulation could prove useful in treating secondary complications in diabetic patients.

\section{Experimental}

\subsection{Chemicals and instrumentation}

All chemicals were purchased from Merck (Darmstadt, Germany) and Sigma-Aldrich Chemie (Steinheim, Germany) unless otherwise noted. The $20 \%$ solution of HSA (96\% purity, containing $0.40 \mathrm{~mol} \mathrm{SH}$ per mol HSA) was purchased from Baxter (Vienna, Austria).

Spectrophotometric measurements were performed using a Beckman DU-50 spectrophotometer (Fullerton, CA, USA). Fluorescence spectra were obtained on a Fluoromax-4 Jobin Yvon (Horiba Scientific, Japan) spectrofluorimeter.

\subsection{Serum samples}

Blood samples were collected from patients with type 2 diabetes who were hospitalized due to poor metabolic control (HbA1c $>10.0 \%$ ) and healthy volunteers of appropriate age and sex. Informed consent was sought from all participants. Blood was allowed to clot at room temperature, and serum was separated by centrifugation $(4000 \mathrm{~g}, 10 \mathrm{~min})$ and used immediately for HSA isolation.

\subsection{Isolation of HSA}

HSA was isolated from serum by ammonium sulphate (AS) precipitation using a two-step protocol following the method of Jovanovic et al. ${ }^{32}$ Briefly, a stock solution of saturated AS (pH 7.4) was added to the serum sample until a concentration of $54 \%$ AS was reached. The precipitated proteins were removed by centrifugation at $5000 \mathrm{~g}$ for $10 \mathrm{~min}$ and the supernatant containing HSA was collected. In the second step, a stock solution of saturated AS ( $\mathrm{pH}$ 7.4) was added to the supernatant up to a final concentration of $70 \%$ AS. The precipitated HSA was separated by centrifugation at $5000 \mathrm{~g}$ for $10 \mathrm{~min}$, and the HSA pellet was resuspended in $0.1 \mathrm{M}$ sodium phosphate buffer ( $\mathrm{pH}$ 7.4). To eliminate AS, HSA solution was further diluted by the same buffer and concentrated by ultra-filtration (Ultracel$10 \mathrm{~K}$, Millipore). The obtained HSA solution was used for further analyses.

\subsection{Thiol quantification}

Serum total free thiol groups (protein and nonprotein, i.e., total thiol content) and HSA-SH content were determined spectrophotometrically according to a modified Ellman's method. ${ }^{33}$ DTNB reagent (5,5'-dithiobis-(2-nitrobenzoic acid), $100 \mu \mathrm{L}$ of $2 \mathrm{mM}$ solution) was mixed with equal volumes of sample and $1 \mathrm{M}$ Tris buffer (pH 8.0) and brought up to $1000 \mu \mathrm{L}$ with water. Absorbance was measured after $30 \mathrm{~min}$ at room temperature at $412 \mathrm{~nm}$ against the sample and reagent blanks. The concentration of thiols was calculated by using the molar extinction coefficient (13600 $\mathrm{mol} \mathrm{L}^{-1} \mathrm{~cm}^{-1}$ ). Values were expressed in $\mathrm{mol} \mathrm{L}^{-1}$ for serum and mol SH per mol HSA.

\subsection{HSA-copper(II) content}

This was quantified by using bathocuproinedisulfonic acid disodium salt (BCDS) as the chelator. The BCDS-Cu(I) complex exhibits a maximum of absorbance at $480 \mathrm{~nm}$. Absorbance was recorded after mixing the samples with ascorbate $(800 \mu \mathrm{M})$; in order to reduce $\mathrm{Cu}(\mathrm{II})$ to $\mathrm{Cu}(\mathrm{I})$ and $\mathrm{BCDS}(400 \mu \mathrm{M})$ against the sample and reagent blanks. Measurements were performed in triplicate and at room temperature. The concentration of copper(II) ions was calculated using a calibration curve prepared for $\mathrm{CuSO}_{4}$ in PBS (5-200 $\left.\mu \mathrm{M}, R=0.9997, P<0.0001\right)$. Values were expressed in mol per mol HSA.

\subsection{Preparation of highly reduced HSA (mercapto-HSA)}

Commercial HSA contains $0.4 \mathrm{~mol} \mathrm{SH}$ group per mol HSA, so for experiments in which the HSA-SH content needed to be higher than 0.4 mol-SH per mol HSA, commercial HSA was reduced with dithiothreitol. Prior to the reduction, the content of the HSA-SH group was determined. An appropriate amount of HSA was mixed with dithiothreitol at a molar ratio of $1: 1$ (molar content of oxidized thiol group : dithiothreitol) for $1 \mathrm{~h}$ at $37{ }^{\circ} \mathrm{C}$ in $0.1 \mathrm{M}$ sodium phosphate buffer, $\mathrm{pH}$ 7.4. Subsequently, dithiothreitol was washed away from HSA with $0.1 \mathrm{M}$ sodium phosphate, pH 7.4, using an Ultracel-30K device (Millipore, USA). After this treatment, the HSA-SH content was 0.89 mol SH group per mol HSA.

\subsection{Preparation of in vitro carbonylated HSA}

Carbonylated HSA was prepared by incubating $0.5 \mathrm{mM}$ HSA with MG $(10 \mathrm{mM})$ at $37{ }^{\circ} \mathrm{C}$ for $24 \mathrm{~h}$ in PBS $(\mathrm{pH}=7.4)$. Following incubation, samples were washed with PBS from any unreacted MG using an Ultracel-30K Millipore ultrafiltration device. 


\subsection{Preparation of $\mathrm{HSA}-\mathrm{Cu}$ (II) complexes}

An aliquot of $\mathrm{CuSO}_{4}$ solution in $10 \mathrm{mM}$ PBS ( $\mathrm{pH}=7.4$ ) was added to HSA samples $(0.5 \mathrm{mM})$ in order to obtain HSA-Cu(II) complexes $(0.05,0.1$ and $0.2 \mathrm{~mol}$ of copper(II) per mol HSA for Complexes I, II and III resp.). The mixture was incubated for $40 \mathrm{~min}$ at $4{ }^{\circ} \mathrm{C}$ in the dark (according to Gryzunov et al. ${ }^{34}$ ). Any unbound copper(II) ions were removed by washing the samples five times with PBS $(1: 15$, vol/vol; $10 \mathrm{mM}, \mathrm{pH}=7.4)$ using an Ultracel-30K device (Millipore, USA).

\subsection{HSA assay}

HSA concentration was measured by a Biuret reaction, ${ }^{35}$ using a HSA standard curve (concentration range from 1 to $100 \mathrm{~g} \mathrm{~L}^{-1}$, $R=0.999)$.

\subsection{Fluorescence spectroscopy}

The protein concentration used for fluorescence measurements was $2 \mu \mathrm{M}$. The spectra were recorded in the wavelength range of 300 to $450 \mathrm{~nm}$ following excitation at $295 \mathrm{~nm}$ using a quartz cell (1 $\mathrm{cm}$ path length) and slit widths $(4 \mathrm{~nm})$. Each spectrum was the average of two scans and the respective blanks of PBS were used for the correction of all fluorescence spectra.

\subsection{Native PAGE}

Native-PAGE (polyacrylamide gel electrophoresis) was performed according to the manufacturer's recommendations using a Hoeffer SE 260 electrophoretic unit (San Francisco, CA, USA), and densitometric analyses of gel by using ImageJ software.

\subsection{Statistical analysis}

Data are expressed as mean values \pm standard deviation from at least three different experiments. Statistical significances were determined by using Student's $t$-test $(P$ values less than 0.05 were considered statistically significant), and statistical correlation by determining Pearson's correlation coefficient.

\section{Results and discussion}

\subsection{The copper(II) binding affinity of carbonylated HSA}

HSA is a metal ion transporter having one high-affinity binding site for copper(II) ions located on the N-terminus. Contradictory results have been observed for copper(II) binding capacity in the amino terminus binding site of glycated HSA. ${ }^{2}$ Having in mind that unbound copper(II) ions can undergo Fenton/Haaber Weiss reaction leading to free radical production, a decrease in HSA copper binding affinity/capacity would contribute to the development of oxidative stress. Therefore, it is of interest to investigate the copper binding affinity of carbonylated HSA.

In order to investigate the influence of HSA carbonylation on copper(II) binding affinity, mercapto-HSA (with $0.879 \mathrm{~mol}$ $\mathrm{SH}$ per mol HSA) was pre-incubated with $10 \mathrm{mM}$ MG for $24 \mathrm{~h}$ at $37^{\circ} \mathrm{C}$. The obtained carbonylated HSA (HSA-MG; with the thiol group content of $0.587 \mathrm{~mol} \mathrm{SH}$ per mol HSA), as well as each mercapto and commercial HSA (0.400 mol SH per mol HSA) were incubated with three different concentrations of copper(II) ions $(0.05,0.10$ and $0.20 \mathrm{~mol}$ of copper(II) per mol HSA). These $\mathrm{Cu}$ (II) concentrations were used because we wanted to have one (nearly) physiological, one slightly elevated and one supraphysiological saturation in order to be able to relate to physiological and pathological conditions during carbonylation with MG, and see if there is a significant difference in $\mathrm{Cu}$ (II) binding capacity of HSA. The content of bound copper in thus formed copper-HSA complexes I, II and III (resp.) was determined (Table 1). The mercapto-HSA sample (with $0.879 \mathrm{~mol} \mathrm{SH}$ per mol HSA) is able to bind all available copper(II) ions. On the other hand, commercial HSA with $0.400 \mathrm{~mol} \mathrm{SH}$ per mol HSA binds 14.4\%, 15.6\% and 29.9\% less copper(II) ions than mercapto-HSA. These results suggested that the copper binding capacity of HSA is positively correlated with HSA$\mathrm{SH}$ content, which is in accordance with the results of Zhang and Wilcox ${ }^{36}$ who found that both in vitro and in vivo $\mathrm{Cu}$ (II) ions preferently bind to albumin with reduced Cys34. The redox state of Cys34 was found to affect the chemical environment of His3, located $\sim 20 \mathrm{~A} \mathrm{away}^{37}$ included in copper coordination besides the N-terminal amine and the first two deprotonated amides.

In comparison to mercapto-HSA, carbonylated HSA samples (with $0.587 \mathrm{~mol} \mathrm{SH}$ per mol HSA) bind copper(II) ions with reduced capacity $(15.2 \%, 15.5 \%$ and $18.2 \%$ resp.) (Table 1 ).

This capacity reduction could be the consequence of decrease in the thiol group content, and also of the conformational changes in HSA (as Lys and Arg residues are also targeted during protein modification with MG). ${ }^{15}$ The changes in the three-dimensional structure were confirmed by recording the fluorescence emission spectra (Fig. 1).

Due to carbonylation of the HSA molecule, the quenching of internal fluorescence (originating from Trp214 after excitation

Table 1 The influence of HSA-SH content on copper(I) binding affinity of mercapto-HSA (0.879 mol SH per mol HSA), commercial HSA (0.400 mol SH per mol HSA) and HSA-MG (0.587 mol SH per mol HSA). Copper-HSA complexes I, II and III are obtained during incubation with $0.05,0.10$ and 0.20 mol of copper(I) per mol HSA, resp. Each experiment was done in triplicate

\begin{tabular}{|c|c|c|c|c|c|}
\hline \multirow[b]{2}{*}{ Copper-HSA complex } & \multicolumn{3}{|c|}{ The content of $\mathrm{Cu}(\mathrm{II})$ ions bound to } & \multicolumn{2}{|c|}{$\begin{array}{l}\text { Decrease in the content of } \mathrm{Cu}(\mathrm{II}) \\
\text { ions bound to HSA (\%) }\end{array}$} \\
\hline & $\begin{array}{l}\text { Mercapto-HSA } \\
\text { (mol per mol HSA } \pm \text { SD) }\end{array}$ & $\begin{array}{l}\text { Commercial HSA } \\
(\mathrm{mol} \text { per mol HSA } \pm \text { SD) }\end{array}$ & $\begin{array}{l}\text { HSA-MG } \\
(\text { mol per mol HSA } \pm \text { SD) }\end{array}$ & $\begin{array}{l}\text { Commercial HSA vs. } \\
\text { mercapto-HSA }\end{array}$ & $\begin{array}{l}\mathrm{HSA}^{-\mathrm{MG}^{a}} \text { vs. } \\
\text { mercapto-HSA }\end{array}$ \\
\hline I & $0.0512 \pm 0.0035$ & $0.0438 \pm 0.0034$ & $0.0434 \pm 0.0013$ & 14.4 & 15.2 \\
\hline II & $0.0959 \pm 0.0038$ & $0.0809 \pm 0.0021$ & $0.0810 \pm 0.0021$ & 15.6 & 15.5 \\
\hline III & $0.2025 \pm 0.0042$ & $0.1420 \pm 0.0064$ & $0.1655 \pm 0.0019$ & 29.9 & 18.2 \\
\hline
\end{tabular}

${ }^{a}$ HSA-MG, HSA carbonylated with methylglyoxal. 


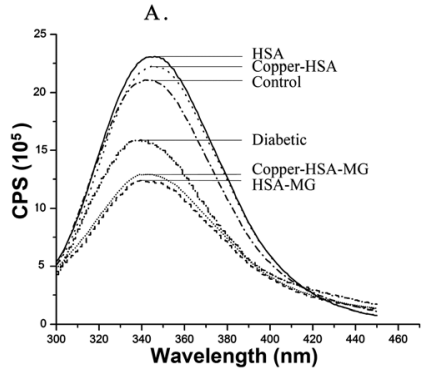

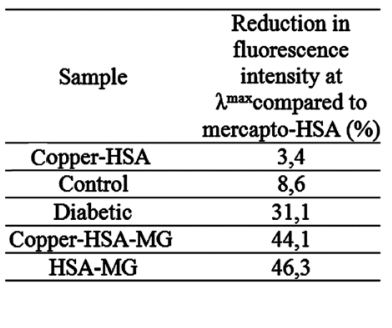

Fig. 1 (A) Fluorescence emission spectra of mercapto-HSA (HSA) and HSA carbonylated with MG (HSA-MG), copper-HSA complex II (copper-HSA) and copper-HSA complex II modified with MG (copper-HSA-MG), HSA isolated from the serum of healthy (control) and diabetic persons (diabetic). Excitation at $295 \mathrm{~nm}$ was used, and emission was recorded in the range from 300 to $450 \mathrm{~nm}$. (B) The reduction of fluorescence intensity of HSA samples in comparison to mercapto-HSA, at the peak wavelength.

of HSA molecule at $295 \mathrm{~nm}$ ) at $\lambda_{\mathrm{em}}=346 \mathrm{~nm}$ by $46 \%$ compared to the unmodified HSA was observed. The differences in fluorescence intensity of HSA and HSA-MG do not arise from changes in their secondary structure (far-UV CD spectra are not shown).

These results confirmed alterations in the capacity of HSA with low HSA-SH content to bind to copper(II) ions. The reaction of carbonylation leads to decrease in HSA copper(II) binding affinity, having important implications considering the involvement of free copper ions in the development of oxidative stress in diabetes (and other diseases with carbonyl stress).

\subsection{Does carbonylation of the Cys34 thiol group influence the release of copper(II) from copper-HSA complexes?}

To answer this question, mercapto-HSA (with 0.879 mol SH per mol HSA) was first pre-incubated with three concentrations of copper(II) ions (0.05, 0.10 and $0.20 \mathrm{~mol}$ of copper(II) per mol HSA). The obtained copper-HSA complexes (I, II and III), as well as mercapto-HSA were subsequently incubated (carbonylated) with $10 \mathrm{mM}$ MG for $24 \mathrm{~h}$ at $37^{\circ} \mathrm{C}$ (copper-HSA I-MG, copper-HSA II-MG, copper-HSA III-MG and mercapto-HSA-MG). The content of HSA-SH groups and the content of HSA bound copper(II) ions in all the samples were determined (Table 2).

The incubation of mercapto-HSA for $24 \mathrm{~h}$ at $37{ }^{\circ} \mathrm{C}$, leads to decrease in HSA-SH content for almost $9 \%$, caused by aerobic oxidation of the Cys34 free thiol group. The decrease in the thiol group content obtained for copper-HSA complexes I, II and III was different $(6.9 \%, 10.3 \%$ and $15.1 \%$ resp.).

These changes implied the existence of the correlation between the thiol group content and the amount of bound copper ions. In order to perceive if this decrease is caused by binding of copper(II) ions (during preparation of complexes I, II and III) or, is the consequence of aerobic oxidation, or both, the content of HSA$\mathrm{SH}$ groups of copper-HSA complexes obtained by incubation of mercapto-HSA with five copper concentrations $(0.05,0.08,0.10$, 0.16 and $0.20 \mathrm{~mol} \mathrm{Cu}(\mathrm{II})$ per mol HSA) during $40 \mathrm{~min}$, was tested (Table 3).

These data showed that loading HSA with copper(II) ions leads to decrease in Cys34 free thiol group content, and that this decrease is proportional to the concentration of copper(II) ions (a Pearson's correlation coefficient $R=0.996$, Fig. 2A).

Comparison of thiol group changes obtained after $40 \mathrm{~min}$ (complex time preparation, Table 3) and $24 \mathrm{~h}$ (incubation time, Table 2) showed no significant differences $(5.8 \%, 8.8 \%$ and $13.7 \%$ vs. $6.9 \%, 10.3 \%$ and $15.1 \%)$. Thus, it could be concluded that binding of copper(II) ions to HSA leads to decrease in the Cys-thiol group content. These results suggest that copper(II) ions, during the course of forming complexes with HSA molecules, could cause the oxidation of Cys34 (and thus affect the redox state of $\mathrm{HSA}^{34}$ ). Densitometric analyses of gel obtained by native-PAGE of mercapto-HSA and copper-HSA complex II (Fig. 2B) showed an increase of $10 \%$ in the intensity of the dimer band in copper-HSA complex II, compared to the dimer band present in mercapto-HSA. This percent corresponds to the percent of decrease in the thiol group content obtained after $24 \mathrm{~h}$ of incubation (10.3\%), suggesting that copper(II) ions cause oxidation of free Cys34-thiol groups into a disulfide bridge formed between two HSA molecules.

The carbonylation of mercapto-HSA (HSA-SH content 0.879 mol per mol HSA, control) with MG for $24 \mathrm{~h}$ caused a decrease in HSA-SH content of $33.2 \%$ (Table 2), which is in accordance with the previously published data. ${ }^{15}$ A similar decrease in the content of HSA-SH groups was obtained for copper-HSA complexes (I-MG, II-MG and III-MG: 31.7\%, 33.3\% and $38.8 \%$, resp.). However, when the decrease in HSA-SH content caused by the preparation of the copper-HSA complexes

Table 2 The influence of carbonylation of mercapto-HSA (with $0.879 \mathrm{~mol} \mathrm{SH}$ per mol HSA) and HSA-copper complexes (I, II and III) with methylglyoxal on the contents of the Cys34-SH group and the HSA bound $\mathrm{Cu}(I)$ ion. Each experiment was done in triplicate and results are presented as mean value \pm SD

\begin{tabular}{|c|c|c|c|c|c|}
\hline \multirow[b]{2}{*}{ Sample } & \multirow{2}{*}{$\begin{array}{l}\text { HSA-SH content following } \\
24 \mathrm{~h} \text { incubation } \\
\text { (mol SH per mol HSA) }\end{array}$} & \multirow{2}{*}{$\begin{array}{l}\text { Decrease in HSA-SH } \\
\text { content compared to } \\
\text { mercapto-HSA (\%) }\end{array}$} & \multicolumn{2}{|c|}{$\begin{array}{l}\text { Content of HSA bound } \mathrm{Cu}(\mathrm{II}) \\
\text { ion (mol per mol HSA) }\end{array}$} & \multirow{2}{*}{$\begin{array}{l}\text { Decrease in } \mathrm{Cu}(\mathrm{II}) \\
\text { ion content }(\%)\end{array}$} \\
\hline & & & $0 \mathrm{~h}$ & $24 \mathrm{~h}$ & \\
\hline Copper-HSA I & $0.818 \pm 0.030$ & 6.9 & $0.0511 \pm 0.0035$ & $0.0496 \pm 0.0035$ & 2.9 \\
\hline Copper-HSA II & $0.788 \pm 0.030$ & 10.3 & $0.0979 \pm 0.0038$ & $0.0920 \pm 0.0015$ & 6.0 \\
\hline Copper-HSA III & $0.746 \pm 0.028$ & 15.1 & $0.2025 \pm 0.0042$ & $0.1855 \pm 0.0032$ & 8.4 \\
\hline Mercapto-HSA-MG & $0.587 \pm 0.049$ & 33.2 & - & - & - \\
\hline Copper-HSA III-MG & $0.538 \pm 0.060$ & 38.8 & $0.2025 \pm 0.0042$ & $0.1675 \pm 0.0019$ & 17.3 \\
\hline
\end{tabular}


Table 3 The changes in thiol group content during the preparation of copper-HSA complexes. The incubation of mercapto-HSA $0.879 \mathrm{~mol} \mathrm{SH}$ per mol HSA) with five different concentrations of copper ions was done in the dark, during 40 min at $+4{ }^{\circ} \mathrm{C}(\mathrm{pH}$ 7.4). Each experiment was done in triplicate

\begin{tabular}{lllr}
\hline & $\begin{array}{l}\text { Content of HSA-SH } \\
\text { groups after incubation }\end{array}$ & \multicolumn{2}{l}{$\begin{array}{l}\text { Decrease in the } \\
\text { ions incubated with }\end{array}$} \\
\cline { 2 - 4 } $\begin{array}{l}\text { HSA-SH group content } \\
\text { mercapto-HSA } \\
\text { (mol per mol HSA) }\end{array}$ & $\begin{array}{l}\text { with Cu(II) ions } \\
\text { (mol per mol HSA) }\end{array}$ & $\begin{array}{llr}\text { (mol SH per } \\
\text { mol HSA) }\end{array}$ & $(\%)$ \\
\hline 0.05 & $0.828 \pm 0.003$ & $0.051 \pm 0.003$ & 5.8 \\
0.08 & $0.806 \pm 0.005$ & $0.073 \pm 0.006$ & 8.3 \\
0.10 & $0.802 \pm 0.010$ & $0.077 \pm 0.011$ & 8.8 \\
0.16 & $0.779 \pm 0.004$ & $0.100 \pm 0.003$ & 11.4 \\
0.20 & $0.759 \pm 0.008$ & $0.120 \pm 0.008$ & 13.7
\end{tabular}

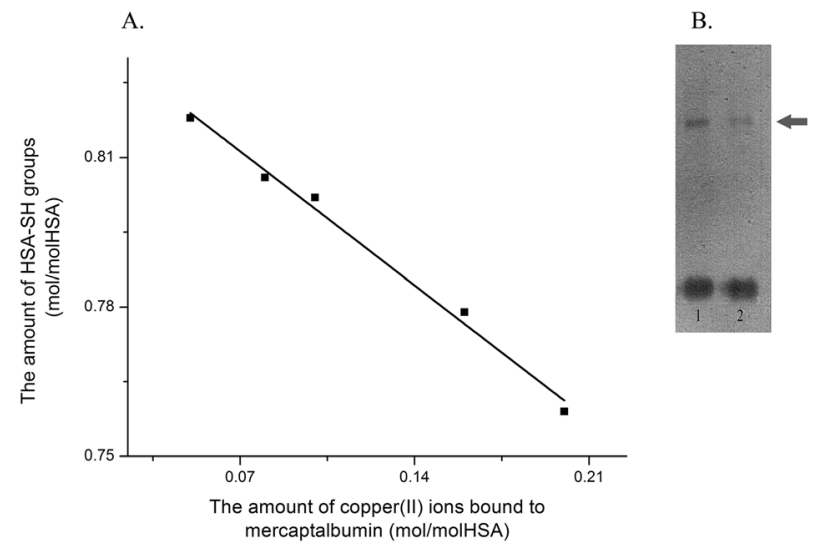

Fig. 2 (A) Correlation between the HSA-SH content and the content of copper(II) ions bound to mercapto-HSA. (B) Native-PAGE of copper-HSA complex II (lane 1) and mercapto-HSA (lane 2). The electrophoresis was performed on $10 \%$ polyacrylamide gel. $2 \mu \mathrm{g}$ of protein was applied per lane. Arrow indicates the HSA dimer band.

(I, II and III), is taken into account, it can be noticed that the percentage of HSA-SH groups which react with MG is lower (24.8\%, 23\% and 23.6\%, resp.). The decrease in the Cys34-thiol group content resulted in the reduction of HSA-bound copper(II) ion content of $15.5 \%, 16.8 \%$ and $17.3 \%$ resp. (Table 2 ). Thus, copper(II) ions are released from HSA molecules during their carbonylation with MG. In order to test if carbonylation of the Cys34 free thiol group is the underlying cause for the release of copper(II) ions from copper-HSA complexes during incubation with MG, the HSA-bound copper(II) and the Cys34-SH group contents were measured in aliquots taken from the incubation mixture (Fig. 3A). The time course curve of Cys34-SH group carbonylation is similar to the copper releasing curve. The release of copper(II) ions occurred in the first three to four hours of the incubation of HSA-copper(II) complex with MG. The ratios between the percentage of reductions (Cys34-SH group content/ HSA bound copper) upon HSA carbonylation were in the range from 0.21 to 2.1 (Fig. 3B).

These results show that similar to copper binding, the release of copper(II) from copper-HSA complexes during carbonylation is strongly dependant on the redox state of the Cys34-thiol group. In addition, it should be underlined that the percentage of decrease in HSA bound copper content, obtained during copper binding capacity investigations of carbonylated HSA-MG (15.2\%, 15.5\% and $18.2 \%$ resp., Table 1 ) and the percentage of copper release from copper-HSA-MG complexes during carbonylation $(15.5 \%$, $16.8 \%$ and $17.3 \%$ resp.) are almost equal. This result would be expected if decrease in thiol group content was considered to be the only cause of observed HSA binding capacity changes, as in both experiments the same concentration of MG was used. Nevertheless, since $\mathrm{Cu}$ (II) ion forms strong tetragonal complexes with biological nitrogen ligands (which is important for fast exchange of ligands in terms of intracellular transfers of this metal $^{38}$ ) the observed release of copper(II) ions bound to HSA could also be the consequence of HSA conformational changes due to carbonylation. The conformational changes in HSA-MG and copper-HSA-MG obtained by florescence spectroscopy, i.e. quenching of internal fluorescence at $\lambda_{\mathrm{em}} 346$ by $46.3 \%$ and $44.1 \%$ (resp.) are nearly identical in comparison to unmodified

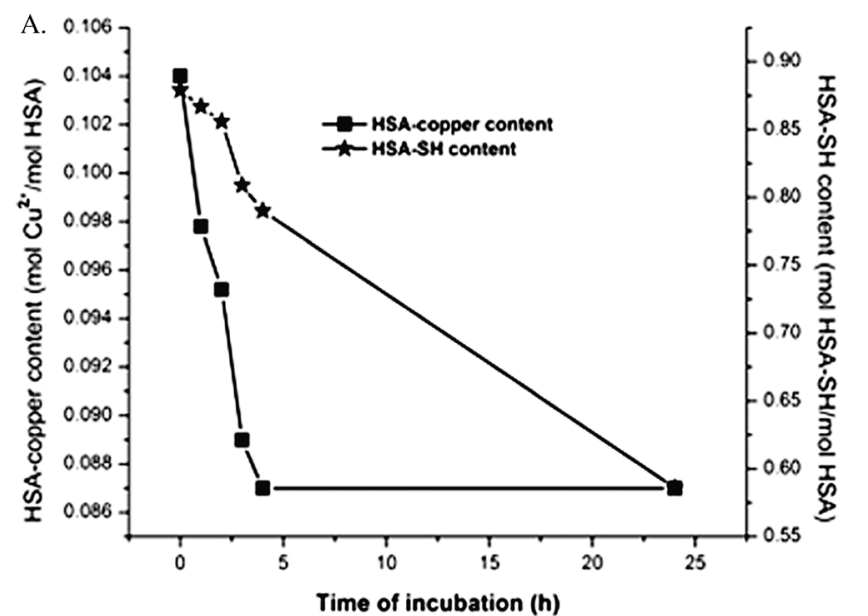

B.

\begin{tabular}{cccc}
\hline $\begin{array}{c}\text { Time } \\
\text { (h) }\end{array}$ & $\begin{array}{c}\text { Cys34-SH content } \\
\text { reduction (\%) }\end{array}$ & $\begin{array}{c}\text { HSA bound copper(II) content } \\
\text { reduction (\%) }\end{array}$ & Ratio \\
\hline 1 & 1.4 & 6.6 & 0.21 \\
\hline 2 & 2.5 & 8.5 & 0.29 \\
\hline 3 & 8 & 14.4 & 0.56 \\
\hline 4 & 10 & 16.3 & 0.61 \\
\hline 24 & 34.2 & 16.3 & 2.1 \\
\hline
\end{tabular}

Fig. 3 (A) The time course curves of reduction in the contents of HSA-bound copper(I) ions and HSA-SH groups during incubation of copper-HSA complex II with $10 \mathrm{mM}$ methylglyoxal $\left(37^{\circ} \mathrm{C}, \mathrm{pH}=7.4\right)$. (B) The ratios of reduction in the Cys34-SH group content and HSA bound copper content upon HSA carbonylation. 
Table 4 Dependence of copper(II) ion release from copper-HSA complexes during oxidation and carbonylation of the Cys34 thiol group

\begin{tabular}{lllll}
\hline & $\begin{array}{l}\text { Decrease in } \\
\text { HSA-SH } \\
\text { content (\%) }\end{array}$ & $\begin{array}{l}\text { Decrease in } \\
\text { the Cu(II) } \\
\text { ion content (\%) }\end{array}$ & Ratio & $\begin{array}{l}\text { Ratio mean } \\
\text { value }\end{array}$ \\
\hline Oxidation & 6.9 & 2.9 & 2.38 & $1.96 \pm 0.36$ \\
& 10.3 & 6.0 & 1.71 & \\
& 15.1 & 8.4 & 1.80 & \\
Carbonylation & 24.8 & 12.9 & 1.92 & $2.12 \pm 0.28$ \\
& 23.0 & 11.5 & 2.00 & \\
& 23.6 & 9.7 & 2.44 & \\
& & & &
\end{tabular}

mercapto-HSA (Fig. 1). The ratio between the percentage of reduction in the Cys 34 thiol group content due to carbonylation of copper-HSA complexes and the percentage of release of copper from complexes is $2.12 \pm 0.28$ (Table 4). The value of this ratio, obtained when oxidation of the thiol group $(1.96 \pm 0.36)$ occurs, is almost equal to the value obtained after carbonylation of the thiol group with MG. Because the HSA conformation and Cys34-SH accessibility ${ }^{39}$ are changed during carbonylation, but not after HSA-SH oxidation (Fig. 1), these results indicate that the binding/release of copper (II) ions by HSA depends mainly on the redox state of the free thiol group. Thus, if the Cys34 residue becomes carbonylated with MG, the copper(II) binding capacity of HSA reduces, and copper(II) ions are released from the complex copper-HSA-MG. The increase in flux of MG and the other reactive dicarbonyl compounds (glyoxal and 3-deoxyglucosone) occurring during carbonyl stress (in diabetes, Alzheimer's disease, renal failure, liver cirrhosis, anemia, uremia, and atherosclerosis $)^{40}$ could lead to the Cys34 side chain carbonylation and therefore to the decrease in HSA-SH and HSA-bound copper contents. This, also, implicates the question of the correlation between these two parameters under real physiological conditions.

\subsection{Changes in the HSA-SH group and HSA-bound copper(II) content in diabetic patients}

To perceive the above given conclusion, sera and HSA of 11 patients with diabetes type 2 and 10 healthy persons were analyzed in order to determine the contents of total serum thiols, total serum copper(II), HSA-SH groups, and HSA-bound copper(II) (Table 5).

HbA1c content in the diabetic group was significantly higher $(p<0.05)$ compared to the control group. In the HSA sample isolated from the serum of diabetic persons (diabetic), the quenching of internal fluorescence at $\lambda_{\mathrm{em}}=346 \mathrm{~nm}$ (originating from Trp214 after excitation of the HSA molecule at $295 \mathrm{~nm}$ ) by $23 \%$, compared to the HSA of healthy person (control), was observed (Fig. 1). Thus, HSA glycation in hyperglycemia leads to change in HSA conformation. In addition, AGEs show fluorescence after excitation at $\lambda_{\text {exc }}$ higher than $290 \mathrm{~nm}$, i.e. they have characteristic excitation at wavelengths in the range of 328 to $370 \mathrm{~nm}$ and fluorescence emission from 378 to $440 \mathrm{~nm}$. The monitoring of the fluorescence at $\lambda_{\text {eksc }} / \lambda_{\mathrm{em}}=365 / 440^{41}$ or $370 / 430^{42}$ was suggested as an indicator of the protein glycation level. Fluorescence emission spectra of HSA samples isolated from the serum of healthy (control) and diabetic persons (Fig. 4), recorded in the
Table 5 HbA1c fraction and the contents of thiol groups and copper(॥) ions in serum and HSA, in diabetes type 2 patients and healthy individuals

\begin{tabular}{|c|c|c|}
\hline & Diabetic patients & Control \\
\hline$n$ & 11 & 10 \\
\hline HbA1c (\%) & $10.25 \pm 1.52^{*}$ & $5.59 \pm 0.53$ \\
\hline Total serum $\mathrm{Cu}^{2+}(\mu \mathrm{M})$ & $34.3 \pm 8.1$ & $28.5 \pm 1.7$ \\
\hline Total serum-SH (mM) & $0.330 \pm 0.059^{* *}$ & $0.427 \pm 0.037$ \\
\hline HSA-SH (mol SH per mol HSA) & $0.457 \pm 0.081^{* *}$ & $0.609 \pm 0.027$ \\
\hline Copper-HSA (mmol per mol HSA) & $10.7 \pm 0.01^{* *}$ & $13.4 \pm 0.01$ \\
\hline
\end{tabular}

wavelength range of 380 to $500 \mathrm{~nm}$ following excitation at $365 \mathrm{~nm}$, are the approval that HSA modification occurred.

The total serum copper(II) ion content in diabetic patients was higher than in the control group, which is in accordance with the results of several studies. ${ }^{43,44}$ In contrast, the total serum thiol content was lower. The HSA-SH group content in the diabetic group is $24.9 \%$ lower compared to the control group, which is in accordance with the results from in vitro experiments and with our previously reported HSA-thiol group content decrease in diabetes. $^{32}$ This difference is statistically significant $(p<0.01)$. As it was expected, based on in vitro experiments, the content of HSA-bound copper(II) ions in the diabetic group was also significantly lower $(p<0.01)$ in comparison to the control group. Decreased levels of HSA-bound copper(II) ions in diabetes were also found by Guerin-Dubourg et al. ${ }^{30}$ When the ratio between the percentages of decrease in the Cys34-SH group content and HSA bound copper content in the diabetic group were compared to the control, the values from 0.51 to 2.54 were obtained (almost identical to the above given in vitro results).

There is a negative correlation between the values for HSASH content and the HbA1c fraction, as well as for total serum thiol content and HbA1c fraction $(R=-0.803, p<0.01 ; R=$ $-0.716, p<0.05$ resp.) in the diabetic group. In contrast, very good positive correlation $(R=0.841, p<0.002)$ between the HSA-SH group contents and values of HSA-bound copper(II) ions was found in the diabetic group. These results confirm our hypothesis that modification of the HSA molecule in patients with diabetes type 2 causes a decrease in the Cys34 thiol group content, leading to the impairment of its copper(II) binding capacity. The increase of the free copper(II) ions in serum could

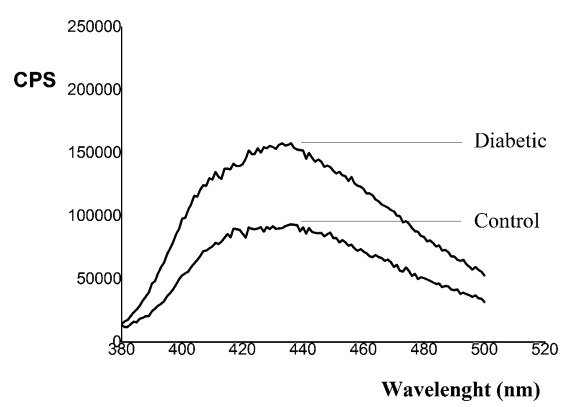

Fig. 4 Fluorescence emission spectra of HSA isolated from the serum of healthy (control) and diabetic persons (diabetic). Excitation at $365 \mathrm{~nm}$ was used, and emission was recorded in the range from 360 to $500 \mathrm{~nm}$. 
contribute to the increase of reactive oxygen species. ${ }^{2}$ Free copper(II) can react with hydrogen peroxide (via the Fenton reaction) leading to the formation of hydroxyl radicals 60 times faster than iron. ${ }^{2}$ Free copper(II) ions increase glucose autoxidation, causing formation of the shorter-chain reactive carbonyl compounds, ${ }^{45}$ and acceleration of alpha-oxoaldehyde formation from early glycation products. ${ }^{46}$ On the other hand, as the HSASH group constitutes an important redox regulator in extracellular compartments, ${ }^{47}$ its decrease due to carbonylation leads also to the decrease of HSA antioxidative potential. ${ }^{48}$ Thus, carbonylation of HSA-SH leads to consequences that cause further enhancement of oxidative and carbonyl stress.

\section{Conclusions}

Overall, the reaction of HSA carbonylation in vitro (with MG) and in vivo (diabetes in which increasing flux of carbonyl species occurs) leads to decrease of its copper(II) binding affinity, i.e. to the release of copper(II) ions from copper-HSA complexes in an extent which depends mainly on the redox state of the Cys34 free thiol group. The decrease of the HSA-SH content and increase of the free copper ions in serum could contribute to further enhancement of oxidative and carbonyl stress.

\section{Acknowledgements}

The Ministry of Education, Science and Technological Development of Serbia supported this work with Grant No. 172049. The authors acknowledge support of the FP7 RegPot project FCUB ERA GA No. 256716. The EC does not share responsibility for the content of the article. The authors would like to thank Dr Vesna Dimitrijevic Sreckovic from the Institute of Endocrinology, Diabetes, and Metabolic Diseases, Clinical Centre of Serbia for kindly providing the samples.

\section{References}

1 T. Peters, Jr, All About Albumin: Biochemistry, Genetics, and Medical Applications, Academic Press, Inc., San Diego, California, 1996.

2 M. Roche, P. Rondeau, N. Ranjan Singh, E. Tarnus and E. Bourdon, FEBS Lett., 2008, 582, 1783-1787.

3 M. Rozga, M. Sokolowska, A. M. Protas and W. Bal, JBIC, J. Biol. Inorg. Chem., 2007, 12, 913-918.

4 W. Bal, M. Sokolowska, E. Kurowska and P. Faller, Biochim. Biophys. Acta, 2013, 1830, 5444-5455.

5 R. M. Walter, J. Y. Uriu-Hare, K. Lewis Olin, M. H. Oster, B. D. Anawalt, J. W. Critchfield and C. L. Keen, Diabetes Care, 1991, 14, 1050-1056.

6 T. Gul Kazi, H. I. Afridi, N. Kazi, M. Khan Jamali, M. Bilal Arain, N. Jalbani and G. Abbas Kandhro, Biol. Trace Elem. Res., 2008, 122, 1-18.

7 M. E. Letelier, S. Sánchez-Jofré, L. Peredo-Silva, J. CortésTroncoso and P. Aracena-Parks, Chem.-Biol. Interact., 2010, 188, 220-227.
8 M. L. Wratten, L. Sereni and C. Tetta, Renal Failure, 2001, 23, 563-571.

9 K. Oettl, V. Stadlbauer, F. Petter, J. Greilberger, C. PutzBankuti, S. Hallstrom, C. Lacknerc and R. E. Stauberb, Biochim. Biophys. Acta, 2008, 1782, 469-473.

10 Z. Rasheed and R. Ali, Life Sci., 2006, 79, 2320-2328.

11 C. G. Schalkwijk and C. D. A. Stehouwer, Clin. Sci., 2005, 109, 143-159.

12 P. Rondeau and E. Bourdon, Biochimie, 2010, 93, 645-658.

13 P. Faure, L. Troncy, M. Lecomte, N. Wiernsperger, M. Lagarde, D. Ruggiero and S. Halimi, Diabetes Metab., 2005, 31, 169-177.

14 T. W. C. Lo, M. E. Westwood, A. C. McLellan, T. Selwood and P. J. Thornalley, J. Biol. Chem., 1994, 269, 32299-32305.

15 J. M. Acimovic, B. D. Stanimirovic and Lj. M. Mandic, J. Serb. Chem. Soc., 2009, 74, 867-883.

16 S. W. Vetter and V. S. K. Indurthi, Clin. Chim. Acta, 2011, 412, 2105-2116.

17 K. Nakajou, H. Watanabe, U. Kragh-Hansen, T. Maruyama and M. Otagiri, Biochim. Biophys. Acta, 2003, 1623, 88-97.

18 K. Mera, K. Takeo, M. Izumi, T. Maruyama, R. Nagai and M. Otagiri, J. Pharm. Sci., 2010, 99, 1614-1625.

19 J. Anguizola, R. Matsuda, O. S. Barnaby, K. S. Hoy, C. Wa, E. DeBolt, M. Koke and D. S. Hage, Clin. Chim. Acta, 2013, 425, 64-76.

20 American Diabetes Association, Diabetes Care, 2008, 31, S55-S60.

21 N. Ahmed, Diabetes Res. Clin. Pract., 2005, 67, 3-21.

22 S. A. Phillips and P. J. Thornalley, Eur. J. Biochem., 1993, 212, 101-105.

23 A. Lapolla, R. Flamini, A. Dalla Vedova, A. Senesi, R. Reitano, D. Fedele, E. Basso, R. Seraglia and P. Traldi, Clin. Chem. Lab. Med., 2003, 41, 1166-1173.

24 P. J. Thornalley, Ann. N. Y. Acad. Sci., 2005, 1043, 111-117.

25 P. J. Thornalley, Biochem. Soc. Trans., 2003, 31, 1372-1377.

26 P. Faure, R. Tamisier, J. P. Baguet, A. Favier, S. Halimi, P. Levy and J.-L. Pepin, Eur. Respir. J., 2008, 31, 1046-1053.

27 P. Matafome, C. Sena and R. Seica, Endocrine, 2013, 43, 472-484.

28 S. S. Mohanty, V. B. Pinnelli, R. Murgod and D. S. Raghavendra, Asian J. Pharm. Clin. Res., 2013, 6, 188-190.

29 M. D. Argirova and B. J. Ortwerth, Arch. Biochem. Biophys., 2003, 420, 176-184.

30 A. Guerin-Dubourg, A. Catan, E. Bourdon and P. Rondeau, Diabetes Metab., 2012, 38, 171-178.

31 I. D. Pavićević, V. B. Jovanović, M. M. Takić, A. Z. Penezić, J. M. Aćimović and Lj. M. Mandić, Chem.-Biol. Interact., 2014, 224, 42-50.

32 V. B. Jovanovic, A. Z. Penezic Romanjuk, I. D. Pavicevic, J. M. Acimovic and Lj. M. Mandić, Anal. Biochem., 2013, 439, 17-22.

33 G. Bulaj, T. Kortemme and D. P. Goldenberg, Biochemistry, 1998, 37, 8965-8972.

34 Y. A. Gryzunov, A. Arroyo, J.-L. Vigne, Q. Zhao, V. A. Tyurin, C. A. Hubel, R. E. Gandley, Y. A. Vladimirov, R. N. Taylor and V. E. Kagan, Arch. Biochem. Biophys., 2003, 413, 53-66. 
35 G. R. Kingsley, J. Biol. Chem., 1939, 131, 197-200.

36 Y. Zhang and D. E. Wilcox, JBIC, J. Biol. Inorg. Chem., 2002, 7, 327-337.

37 J. Christodoulou, P. J. Sadler and A. Tucker, Eur. J. Biochem., 1994, 225, 363-368.

38 L. Banci, I. Bertini, S. Ciofi-Baffoni, T. Kozyreva, K. Zovo and P. Palumaa, Nature, 2010, 465, 645-648.

39 J. M. Aćimović, B. D. Stanimirović, N. Todorović, V. B. Jovanović and Lj. M. Mandić, Chem.-Biol. Interact., 2010, 188, 21-30.

40 P. J. Thornalley, Drug Metab. Drug Interact., 2008, 23, 125-150.

41 S. D. Sharma, B. N. Pandey, K. P. Mishra and S. Sivakami, J. Biochem., Mol. Biol. Biophys., 2002, 6(4), 233-242.
42 H. Zoellner, J. Y. Hou, T. Hochgrebe, A. Poljak, M. W. Duncan, J. Golding, T. Henderson and G. Lynch, Biochem. Biophys. Res. Commun., 2001, 284, 83-89.

43 A. Sarkar, S. Dash, B. K. Barik, M. S. Muttigi, V. Kedage, J. K. Shetty and M. Prakash, Indian J. Clin. Biochem., 2010, 25, 74-76.

44 J. Xu, Q. Zhou, G. Liu, Y. Tan and L. Cai, Oxid. Med. Cell. Longevity, 2013, 2013, 635214, DOI: 10.1155/2013/635214.

45 S. P. Wolff and R. T. Dean, Biochem. J., 1987, 245, 243-250.

46 P. J. Thornalley, A. Langborg and H. S. Minhas, Biochem. J., 1999, 344, 109-116.

47 S. Carballal, B. Alvarez, L. Turell, H. Botti, B. A. Freeman and R. Radi, Amino Acids, 2007, 32, 543-551.

48 P. Faure, L. Troncy, M. Lecomte, N. Wiernsperger, M. Lagarde, D. Ruggiero and S. Halimi, Diabetes Metab., 2005, 31, 169-177. 